\title{
On the Development of Palinurus vulgaris, the Rock Lobster or Sea Crayfish.
}

\author{
By
}

J. T. Cunningham, M.A.

With Plates VIII and IX.

1. Historical Review.

THE history of our knowledge of this subject is complicated and curious, and is not quite correctly narrated in any English publication, not even by Balfour in his account of the development of Crustacea (Comparative Embryology, vol. i). The story begins with the establishment and definition of the genus Phyllosoma by Leach in 1818. Various succeeding zoologists included descriptions of species of Phyllosoma in their works, but the result of all previous investigations are included by Milne Edwards in the comprehensive account of the genus given in his Hist. Nat. des Crustacés, vol. ii, 1837. The state of knowledge at that time may be briefly summarised as follows :-The Crustaceans known by the name Phyllosoma had been found near the surface of the ocean in various parts of the world. They varied in size from less than half an inch to two inches. They were, when alive, of glassy transparency; the body was remarkably flat, and expanded horizontally, while the limbs were long, slender, and biramous. The body consisted of three parts ; firstly, a head having the form of an oval leaf, bearing at its anterior extremity a pair of eyes on long stalks and two pairs of simple antennæ. The mouth was situated beneath the middle or posterior third of the head, and surrounded by an upper and lower lip, a pair of mandibles, and the first pair of maxillæ. The second pair of maxillæ and the first pair of maxillipeds were rudimentary and 
situated behind the mouth. The second part of the body was the thorax, quite as flat but not so large as the head; it was usually broader than long. It presented no trace of a division into segments, but on its lateral edges carried four to six pairs of long, delicate, articulated limbs, each of which was provided with a secondary shorter branch fringed with hairs on each side. The disposition of the abdomen varied; in some species it was distinctly marked off from the thorax and much narrower, sometimes situated in an emargination of the posterior edge of the thorax, and sometimes again it was at its base as broad as the thorax, of which it formed a direct continuation. Usually six or seven segments were visible in the abdomen, the last of which bore biramous flat appendages, like those of the lobster, on each side of the telson. According to these differences in the abdomen, Milne Edwards divided the species of Phyllosoma into three groups: (1) those which had a distinct well-developed abdomen, narrower than the thorax, Phyllosomes ordinaires; (2) those in which the abdomen was rudimentary, and situated in an emargination of the thorax, Phyllosomes brevicaudes; (3) those in which the abdomen was broad and continuous with the thorax, Phyllosomes laticaudes.

Since the date of Milne Edwards' work, various more or less incomplete researches have proved that the forms belonging to the genus Phyllosoma, as defined by the characteristics just described, are the early stages or larvæ of Palinurus and its allies, that is, of the Decapod Crustaceans of the family Palinuridæ or Loricata. Balfour, in his Comp. Embryology, vol. i, p. 477, states that the true nature of Phyllosoma was first shown by R. Q. Couch in a paper on The Metamorphosis of Decapod Crustacea in the Report of the Cornwall Polytechnic Society of 1848, but that Couch did not recognise the identity of his larva with Phyllosoma, which was first done by Gerstäcker. This statement is incorrect, probably because Balfour was unable to refer directly to the Reports of the Cornwall Polytechnic Society, to which I have access in the library of the Plymouth Institution. R. Q. Couch's first paper on The Metamorphosis of Decapod Crustaceans is in the Report of the said Society for 1843. The description of the newly hatched Palinurus there given is quite erroneous. Couch states that he obtained gravid specimens of Palinurus from the fishermen, and kept them in crabpots until the eggs hatched. His description of the hatched larva is as follows :- "The whole animal is smaller and more slender than the young of the lobster. The body is oval, slightly depressed; eyes rather small compared with other species, sessile, marked at its circumference with radiating lines, and situated on a festoon of the dorsal shield, The claws are in four pairs, similar to those of 
the adult, and rather long. The tail is long, extended, and composed of five unequal annulations; it is generally semi-flexed on the abdomen and hid among the claws. On the four superior rings of the tail are situated four pairs of long slender appendages. They are attached to the rings by joints, similar to those of the true claws. At a short distance from the basal joint these organs branch into two long slender branches, which extend nearly one third as long again as the tail; hence the posterior part of the body has a very bushy appearance. The termination of the tail is formed of two small fan-shaped expansions, separated by a shallow notch."

Couch gives a figure of the larval Palinurus in profile, which is as fictitious as his description. It is evident from the description, that he mistook the thorax of the larva for the abdomen, and regarded the true rudimentary abdomen as the last joint of the "tail." In his figure the thorax appears cylindrical instead of flat, and the four long characteristic thoracic limbs of the Phyllosoma are represented by four biramous appendages having a filamentous appearance. But the extraordinary thing is that in the figure, as in the description, there are four unbranched appendages in front of the four biramous, attached to the cephalic portion of the larva which Couch mistook for the cephalothorax. Since, in reality, there is only one elongated articulated appendage in front of the four biramous, namely, the second maxilliped, and as the rest of the oral appendages are quite small and visible only under a lens, it is extremely difficult to understand how Couch invented his figure. It is possible that he supposed all the long appendages that he saw, four pairs, to be on one side, those of the other side being invisible; in this way he may have reached his conclusion that there were eight pairs of limbs in all, four claws on the "body" and four slender appendages on the tail. However this may be, this first description is quite worthless, and there is no reference in it to Phyllosoma.

In the Report of the same Society for the following year, 1844, there is a second paper on the Metamorphosis of Decapod Crustacea, but all that it contains concerning Palinurus is that the young had been examined again with the same results as before.

In the Report of the Meeting of the British Association in 1857 there is a short paper by R. Q. Couch, entitled On the Embryo State of Palinurus vulgaris. The description of the larva there given is much more correct than that previously published by the same observer. It runs thus:- "The carapace is globular, oval, slightly pointed or produced both at the anterior and posterior margin, and also slightly contracted anteriorly, so as to give the appearance of a rostrum. The abdomen is moderately long, and from four of the six annulations of which it is composed arise eight pairs of tendril-like

NEW SERIES.-VOL. II, NO. II. 
appendages. These tendrils are long, slender, and dichotomous. Their double character commences at the third joint; for the remainder of their length they are nearly equal, and are covered with strongly marked spines; their termination is pointed. The caudal extremity is simple, contracted, pointed, and somewhat oval ; on the centre of the rostrum is a dark spot; the eyes are placed on enormously long and stoutly club-shaped peduncles, which are attached by very narrow and slender points. The pedunculated eyes are about two-thirds as long as the carapace. The contrast between the young of the present species and others is very great. In them the eyes are sessile ; in this enormously pedunculated. In them the limbs are beneath the carapace; in this they are attached to what, for clearness, I have called the abdominal rings. Instead, therefore, of belonging to the genus Zoe, this would be placed in Phyllosoma of Milne Edwards, as belonging to the Stomapodes."

Here, then, although it is evident Couch did not know much of the morphology of Crustacea, we have a great improvement on his former description. He evidently means to describe four pairs of biramous appendages; he mentions the long peduncles of the eyes, and the median eye (dark spot he calls it) on the rostrum. In this paper the comparison of the larva of Palinurus with Phyllosoma is made for the first time, although the importance of the comparison remained to be developed by men who understood the structure of Crustaceans better than Couch. In the British Association Report no figures accompany Couch's paper, but it is reprinted in the Natural History Review, vol. iv, 1857, with a plate (pl. xvii). On this plate is given a figure of the Palinurus larva from the ventral aspect. The figure is recognisable, though not very accurate. It gives fairly well the general shape of the body, the eyes, antennæ, and four pairs of long thoracic appendages. But the shape of the thorax is incorrect, as also that of the appendages, especially of the exopodites, while the appendages in front of the third maxilliped are entirely wanting from this figure and the rest of the plate.

In a Report on the Progress of Entomology in the Archiv f. Naturgeschichte, 1858, Gerstäcker speaks of the similarity of Couch's figure of the Palinurus larva with Phyllosoma, but does not mention that Couch made the comparison himself.

Independently of Couch, Gerbe in 1858 made the observation that the newly hatched larva of Palinurus had the characters of the genus Phyllosoma. Gerbe's studies were made at the Laboratory of Concarneau in Brittany, and were briefly described by Coste in the Comptes Rendus of 1858. Coste's publication was not accompanied by figures, but stated that Gerbe would be able, from material supplied by the aquaria of Concarneau, to publish at a future time a 
- full account of the metamorphoses of Palinurus, an object which has never yet been realised either by Gerbe or anyone else.

In 1863 Claus, in an account of observations made at Messina (Zeit. f. wiss. Zool.), described the embryo of Palinurus before hatching, and compared it with young Phyllosomata captured in the sea. He found differences in this comparison which appeared to him inexplicable on the view that Phyllosoma was the larva of the Palinuridx. Spence Bate also came forward to oppose the correctness of the conclusions of Couch and Gerbe, in a paper in the Ann. and Mag. Nat. Hist., ser. 4, vol. ii.

Dohrn, however, in 1870 (Zeit. f. wiss. Zool.) published an important confirmation of the identity suggested by Couch and Gerbe. He gives a description of the development of Scyllarus in the egg, and of the newly hatched larva, which he shows to be identical with the smallest Phyllosoma obtained by Claus from the sea. He shows that the second maxilla gets smaller during the end of the embryonic period, while the first maxilliped disappears altogether before hatching. The second antenna is much shorter than the first.

In the embryo of Palinurus, at an early stage, the second antenna is longer than the first; the second maxilla is biramous, the inner branch smaller than the outer. The first maxilliped is at first distinctly biramous, but the branching disappears; the appendage becomes simple, but does not disappear as in Scyllarus. The abdomen is rounded at the end, and the last pair of appendages is indicated. In the embryo, when ready to hatch, Dohrn states that the first maxilliped is quite short and thick, and appears to have a prominence near the base, which probably developes later into a branchial plate. Dohrn gives no figure nor further description of the hatched larva.

In 1873 Ferd. Richters published in the same Zeitschrift a paper containing the results of a critical examination of a large collection of specimens of Phyllosoma from the Hamburg Museum. Richters has shown by tracing successive stages in his specimens, and com. paring them with the observations of Claus and Dohrn, that all those Phyllosomes which possess the following three characters belong to the genus Palinurus, which is distinguished from the other genera of its family, such as Scyllarus, by having long, cylindrical, multiarticulate second antennæ, whereas the others have short, flat, broad second antennæ with few segments. The three distinguishing characters of the Palinurus Phyllosomes are-

(1) The second antennæ are longer than the first in the earliest stages, and later on always remain cylindrical ; while in the Scyllarus Phyllosomes the second antennæ are in the earliest stages much shorter than the first, and soon become broad and flat. 
(2) The abdomen is sharply marked off from the thorax, being: much narrower at its base than the latter.

(3) The articulation of the thorax with the abdomen is on the same level with the origin of the last pair of thoracic limbs.

Thus Richters shows that the forms which Milne Edwards distinguished as Phyllosomes ordinaires are the larvæ of Palinurus, or genera belonging to the Palinurus division of the Loricata.

But here we come upon a point which requires elucidation. Richters states that the first maxilliped is completely wanting in the youngest larvæ of the Palinurus series; he points out that Dohrn himself describes a reduction of the first maxilliped as having taken place in the embryo almost ready to hatch, and then says that this last stump also, without doubt, disappears, since in the youngest Palinurus Phyllosomes which he examined no trace of this appendage was to be discovered.

The last publication I have to refer to is Spence Bate's Report on the Decapoda macrura collected by the "Challenger." That author says concerning the larvæ of Palinurus, that it has been found impossible to keep them alive in aquaria any time after hatching, and that although, no doubt, there are large numbers of these larvæ in the sea off our south-west coast, only solitary specimens of the Phyllosoma form have been occasionally taken. Spence Bate does not figure the hatched larva of our common Palinurus, the true Phyllosoma, but gives instead a figure of the nearly ripe embryo taken from the egg, and this is by no means perfectly similar to the free larva. With regard to the question of the first maxilliped Spence Bates' descriptions throw no light upon it, as he does not go into the details of the oral appendages in his specimens. He was not apparently acquainted with Richters' paper, for he attributes to Palinurus, a specimen of Phyllosoma having the characteristics of those larvæ which Richters has shown to belong in all probability to Ibacus or Paribacus, or, at all events, to develop into forms with short, flat antennæ.

We find then, from the above survey of the literature that although it is clear that Palinurus vulgaris is developed from a Phyllosoma, no single figure or detailed description of any larval stage, known certainly to belong to this species, has been published except those of Couch, which are unsatisfactory. Claus has published figures of Phyllosomes taken at Messina, the smallest of which Dohrn proved afterwards to be identical with the larva of Scyllarus arctus, now called Arctus ursus, which also occurs, though rarely, in the neighbourhood of Plymouth. The newly hatched larva of Palinurus has been obtained in aquaria several times, e. $g$. by Gerbe at Concarneau, by Dohrn at Messina, and by Alfred Lloyd 
at the Crystal Palace. But no correct figure of it is in existence, nor have its later stages been described. I now proceed to the description of my own observations.

\section{Observations on the Larva of Palinurus vulgaris.}

In July, 1889, a large number of larvæ were hatched from a berried crayfish in one of our tanks at the Plymouth Laboratory, and I preserved some hundreds of these, but did not then study them. This year, on the 9th July, when I was working a large net made of mosquito netting at the surface, a little to the north of the Eddystone, I obtained a number of Phyllosomes of different sizes and stages. On the 16th I obtained a still larger number in the same net to the south of the Eddystone. Hitherto they have only been very rarely taken on the south coast of England, and then, according to Spence Bate, only solitary specimens. The reason of this seems to be merely that suitable nets have not been used in the right place at the right time of year. These larvæ apparently do not occur near shore, for we have never taken them before in our ordinary tow-nets worked within a mile or two of the coast. At any rate it is interesting to find that some hundreds may be taken in about an hour in the neighbourhood of the Eddystone in July, with a net whose meshes are about $2 \mathrm{~mm}$. in diameter, and whose mouth is 8 feet by 6 feet in area. On the two occasions on which I obtained the larvæ, I captured them only when towing the net at the surface, not when it was sunk to some depth.

The newly hatched larva of Palinurus is $3.1 \mathrm{~mm}$. in length from the anterior border of the cephalon to the posterior extremity of the abdomen. The second antenna is almost, but not quite, as long as the first, and neither of them is divided into joints. The thorax is provided with four pairs of very much elongated appendages, namely, the third maxilliped and the first, second, and third ambulatory limbs or pereiopods. These appendages all have six joints, and from the end of the second joint springs an exopodite consisting of a larger number of short joints, and fringed with long feather-like bristles. The exopodite of the third pereiopod is not completely developed, having slight indications of one or two joints and no bristles. Of the oral appendages, the mandibles and first maxillæ are fully developed and functional; the second maxilla is rather large and foliaceous, and extends away from the median line; the first maxilliped is not wanting, but rudimentary, being represented by a simple, small, but distinct conical stump. The second maxilliped is a slender six-jointed appendage, not extending beyond the 
cephalon, and destitute of even the rudiment of an exopodite. The fourth and fifth pereiopoda are not yet developed, but represented by two minute rounded buds on either side of the root of the abdomen. The abdomen is without developed appendages, but the sixth pair of pleopods is indicated already by a slight rounded outgrowth on each side of the telson. The termination of the telson is truncated, without the slightest trace of bifurcation (Pl. VIII).

Among the Phyllosomes I obtained from the sea there are all sizes and stages, from the newly-hatched stage just described, up to one $7 \mathrm{~mm}$. long, which is the largest and most developed I have yet obtained. The developments that have taken place at this stage are as follows:-The second antenna is now a little, but not much longer than the first. Two basal joints have been differentiated in the first antenna, and from the end of the second has grown out a simple process, the commencement of the internal filament. One nodal division is also visible in the basal portion of the second antenna. The exopodite has began to sprout out from the second joint of the second maxilliped, but the rudimentary stump of the first maxilliped, and the rest of the oral appendages, are quite unchanged. The exopodite of the third pereiopod is fully developed, and the fourth and fifth pairs of pereiopoda have developed considerably, the fourth being biramous and almost as long as the abdomen, the fifth still simple and somewhat shorter. The pleopods of the abdomen are considerably developed. The sixth pair or swimmerets are of some length and distinctly biramous, while the four preceding pairs are also visible, and each commencing to divide into exopodite and endopodite. No appendage is developed at all on the first abdominal segment. The cephalic shield which, in the newly-hatched stage, covered only the second maxilliped, leaving all the rest of the thorax with its appendages free, now extends back so as to cover the origin and base of the third maxilliped (Pl. IX).

There can be no doubt at all that the Phyllosomes I have obtained belong to Palimurus vulgaris ; Dohrn's and Richters' investigations have shown clearly that the larvæ of Scyllarus can be distinguished from those of Palinurus at all stages, and Scyllarus arctus (Arctus ursus) is the only other species of the family which occurs near Plymouth, and this form is very rare. It becomes possible, therefore, to identify the Phyllosoma larvæ of Palinurus vulgaris if they have been sufficiently described or figured in previous literature. It is not possible to identify satisfactorily the forms described by Milne Edwards and Richters ; they come from distant coasts, such as those of Africa, Asia, and New Guinea. However, it may be mentioned that Richters is very possibly wrong in stating that the first maxilliped was wanting in his youngest Palinurine form, $7 \mathrm{~mm}$. 
in length, since his figure of the appendages in this form is not conclusive, but suggests the idea that he has figured the rudimentary first maxilliped and mistaken it for the second maxilla.

It is more interesting to note that of the stages obtained and figured by Claus at Messina, while the oldest and youngest belong to Scyllarus, all the others, that is all those figured on Z. f. w. Z., Bd. xiii, pl. xxvi, are stages in the development of Palinurus vulgaris. The youngest of these stages is described as $4 \mathrm{~mm}$. long, and therefore has not long been hatched. It agrees, except in one or two very minute details, due, I think, to slight mistakes in drawing, with the newly hatched larva I have described, and, above all, both in the description and figure of Claus, the first maxilliped is represented as a short papilla-like process, exactly similar to that in my specimens. Claus figures and describes two other stages, which also I identify as belonging to Palinurus vulgaris; one of these is $14 \mathrm{~mm}$. long, the other $21 \mathrm{~mm}$; ; both, therefore, older than the oldest of my specimens. In the former, the thorax extends back over the third maxilliped in the older stage $(21 \mathrm{~mm}$.), still further, covering the base of the first pereiopod. In this oldest stage of Claus the antennæ have almost acquired the adult form, and the fourth and fifth pereiopoda are longer than the abdomen, although the fifth is still destitute of exopodite. In both these older stages the first maxilliped has considerably developed, consisting of a long cylindrical appendage borne on a short stump.

Thus it is evident that the Phyllosoma of Palinurus vulgaris reaches a length of more than $21 \mathrm{~mm}$. before it begins to lose the characteristic flattened form of the larva. The smallest Palinurus observed by Richters was $25 \mathrm{~mm}$., or 1 inch in length, and had all the characters of the adult. The later stages of transition between the Phyllosoma and the young Palinurus have still to be discovered.

I hoped to obtain stages later than those I have here described, but unfortunately the weather during the latter half of July and the whole of August was persistently stormy, and it was impossible to collect in the open sea. In September I resumed my expeditions, but obtained no more Phyllosomes. 


\section{DESCRIPTION OF PLATES VIII AND IX,}

\section{Illustrating Mr. Cunningham's paper " On the Development of Palinurus vulgaris, the Rock Lobster or Sea Crayfish."}

\section{PLATE VIII.}

Frg. 1.-Newly hatched larva of Palinurus vulgaris; ventral surface, magnified 19 diameters. From a specimen hatched in the Aquarium, July, 1889.

\section{PLATE IX.}

Fig. 2.-Phyllosoma stage of Palinuris vulgaris, $7 \mathrm{~mm}$. long, taken in large tow-net south of Eddystone, July 16th, 1891. The Roman figures in this and the preceding figure indicate the appendages (excluding the eye-stalks), numbered from the first antenna backwards.

FIG. 3.-The oral appendages of a larva $4.5 \mathrm{~mm}$. long. $\quad u$. $l$. Upper labium. $\quad$. $l$. Left half of lower labium. $m d$. Mandible. $1 m x$. First maxilla. $2 m x$. Second maxilla. 1 mxp. First maxilliped. 
Fig. 1.

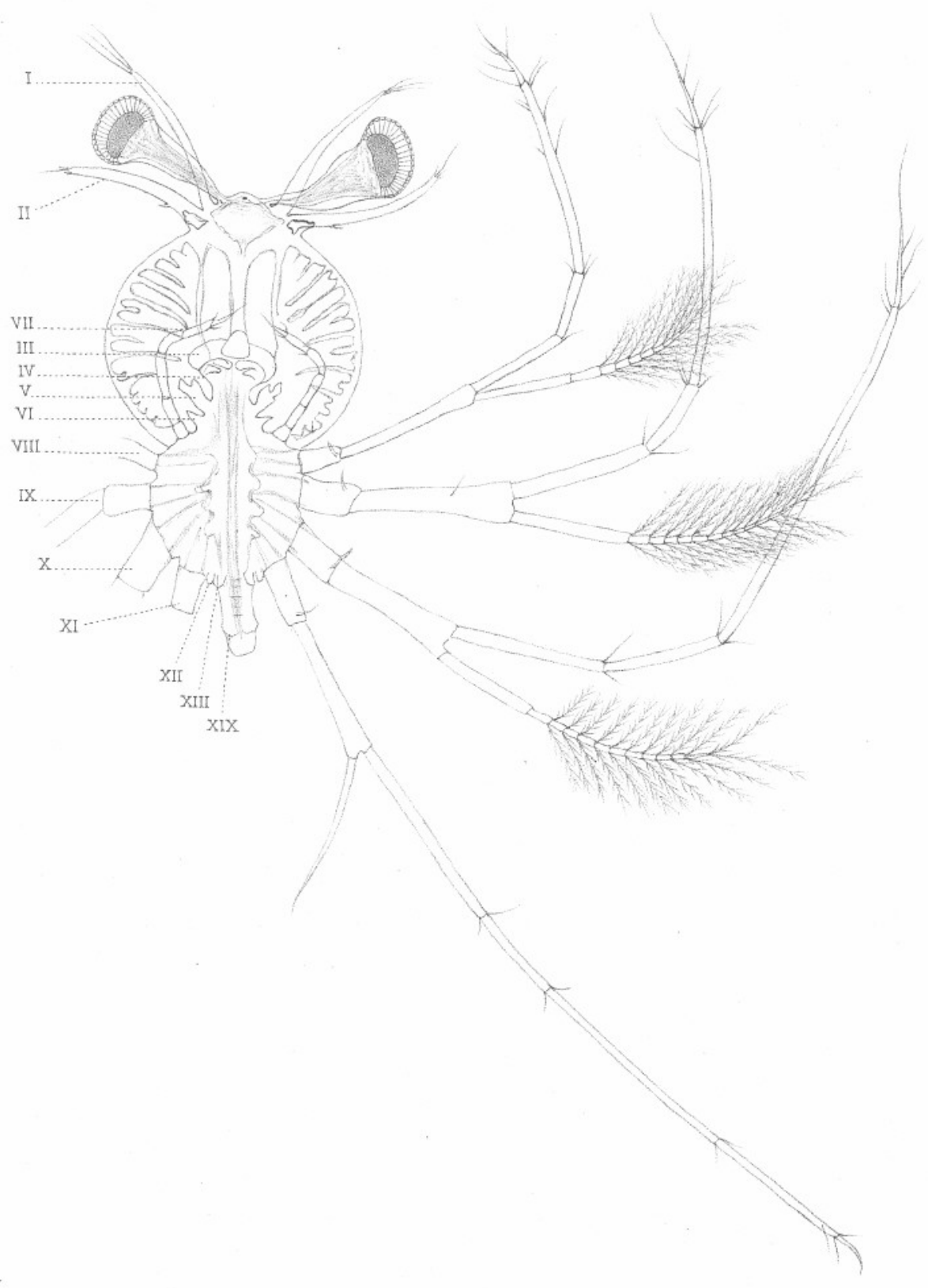


Fig. 2 .

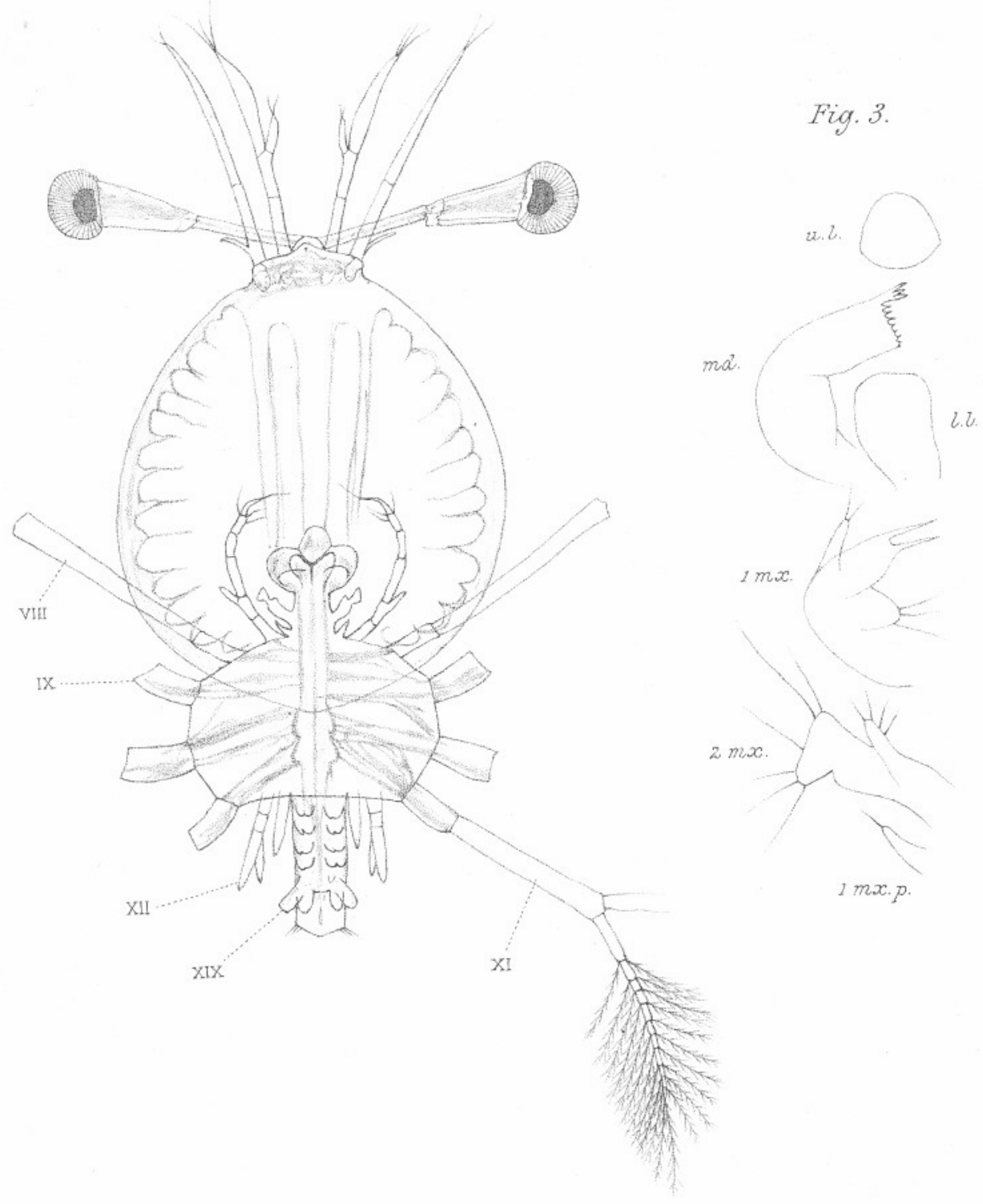

